Marcus Vinicius Rossi da Rocha ${ }^{1,2}$

\title{
Brasil em transição? A difícil articulação entre crenças, instituições e desenvolvimento
}

"Brazil in Transition: beliefs, leadership and institutional change" (2016), escrito por Lee J. Alston, Marcus André Melo, Bernardo Mueller e Carlos Pereira argumenta que o Brasil estaria passando por uma transição crítica em direção ao desenvolvimento social e econômico. Essa transição ocorreria pois uma liderança foi capaz de aproveitar uma janela de oportunidade para promover novas crenças que, por sua vez, determinam o surgimento de novas instituições, responsáveis por desenvolver o país. Insere-se, portanto, dentro da tradição de estudos que buscam explicar o desenvolvimento econômico por fatores políticos e sociais (por exemplo, Barrington Moore Jr, Samuel Huntington, Theda Skocpol) e dentro da agenda mais recente sobre processos de mudança institucional (por exemplo, James Mahoney, Kathlen Thelem, Paul Pierson e Wolfgang Streek).

Os autores argumentam que indicadores tais como PIB per capita, resultado do PISA ou percepção da corrupção não são capazes de abarcar um fenômeno complexo como o desenvolvimento. Porém, a análise longitudinal mostraria que há uma melhora contínua e gradual nesses indicadores, sobretudo na redução da pobreza e da desigualdade. Mais importante, as instituições necessárias para este verdadeiro milagre (p. 3) já teriam sido criadas, resultado da

Doutorando em Políticas Públicas, Mestre em Ciência Política, Bacharel em Ciências Sociais. Universidade Federal do Rio Grande do Sul, Porto Alegre, RS, Brasil.<marcus.rocha@ufrgs.br>, 051 99120 6041. Currículo Lattes: <http://lattes.cnpq.br/7716793067440072>

2 Pesquisador do grupo de pesquisa do CNPq Núcleo de Estudos sobre Corrupção, presidente da Student Section da Latin American Studies Association e integrante do projeto Atlas da Política Municipal do Brasil: partidos, burocracias e políticas públicas. Visiting Fellow no Center for Latin America \& Latino Studies da American university entre 2017 e 2018. 
afirmação de crenças (beliefs) ${ }^{3}$ na inclusão social e na aversão à inflação. Estas instituições consolidariam um Brasil "economicamente ortodoxo, politicamente aberto, e socialmente inclusivo, com todas essas três áreas marcadas por um respeito geral pelas regras" (Alston, Melo, Mueller e Pereira, 2016, p. 6).

A pesquisa utiliza um modelo de análise contextual do desenvolvimento que considera instituições, janelas de oportunidade, liderança, crenças e coalizão dominante. O objetivo desta metodologia é realizar uma análise densa e aprofundada do fenômeno do desenvolvimento socioeconômico. O modelo é desenvolvido a partir do caso do Brasil, com a análise de três momentos chave entre 1964 e 2014 e aplicado à análise do caso da Argentina entre 1912 e 1946 com o objetivo de testar seu potencial dedutivo.

O objeto de análise, portanto, não são os resultados de políticas públicas manifestos em indicadores, mas as crenças e instituições que seriam os principais mecanismos de incentivo e constrangimento dos atores (p. 14). Crenças são definidas como "construções mentais que relacionam instituições e com seus resultados" (p. 14) ou ainda, de forma mais ampla, "a visão dos atores sobre como o mundo funciona” (p. 180). São duas as crenças a emergir no Brasil após 1985, responsáveis por influenciar a criação de instituições que colocam o Brasil na iminência de uma transição crítica rumo a se tornar um país desenvolvido: a crença na inclusão social e a aversão à inflação.

A mudança institucional seria resultado da mudança nas crenças, especialmente naquelas abraçadas pela coalizão dominante (dominant network) que é o conjunto de organizações e atores com poder político para mudar as instituições formais. Enquanto as expectativas da sociedade combinam com os resultados de políticas, ocorrem apenas mudanças marginais e as instituições funcionam no automático. Porém, quando os resultados políticos e econômicos divergem daqueles esperados as crenças centrais da coalizão dominante são perturbadas e abre-se uma janela de oportunidades na qual há abertura na sociedade para o estabelecimento de novas

3 Todas as citações diretas do livro foram traduzidas pelo autor desta resenha. Excepcionalmente, conceitos utilizados pela literatura científica são referidos em inglês. 
crenças. A janela de oportunidades é um ciclo que se encerra com mudança nas crenças centrais da coalizão dominante e na maioria dos cidadãos (Alston, Melo, Mueller e Pereira, 2016, p. 176).

Para tanto, é fundamental que haja uma liderança (Alston, Melo, Mueller e Pereira, 2016, p. 25) capaz de compreender o momento (ser capaz de entender o problema social e identificar que a janela se abriu); resolver o problema coordenação; e de ter autoridade moral. A transição crítica pela qual o Brasil estaria passando só teria sido possível, por exemplo, porque Fernando Henrique Cardoso reuniu todas essas qualidades.

Reunir todas essas características -líder, crenças, coalizão dominante, janela de oportunidades, instituições- em um mesmo momento não é fácil. Os autores argumentam que, embora sem indicadores muito fortes neste momento, as instituições exercerão seu papel causal esperado, pois: "Nós prevemos que o Brasil vai estabelecer instituições que levam ao crescimento econômico estável e menos política disfuncional e corrupção. Sustentar esse caminho vai ao Brasil fazer a transição dos países de baixo crescimento para os de alto crescimento no mundo" (Alston, Melo, Mueller e Pereira, 2016, p.17).

São analisados três momentos importantes da história brasileira e suas respectivas coalizões dominantes e crenças. O primeiro momento ocorre entre 1964 e 1984, período marcado pela crença no desenvolvimentismo e pela relação da tecnocracia do regime com os capitais nacional e internacional. A coalizão dominante que envolvia tais atores compartilhava a crença de que o desenvolvimento deve ser coordenado pelo Estado e que o crescimento deveria preceder à redistribuição; em segundo lugar, o momento constitucional (1984-1993), marcado pela crença na inclusão, mas também pela falta de legitimidade de Sarney e de sua coalizão. O resultado dessa inclusão insustentável (p. 38) é o descontrole das contas públicas e a hiperinflação dos anos 80; finalmente a crença na inclusão social com aversão à inflação afirma-se em período central no qual a mudança institucional é gestada (1994-2014). O sucesso do Plano Real e a liderança de FHC na construção de uma 
coalizão dominante ampla em apoio às reformas de mercado são determinantes para a consolidação das instituições nesse período. Os dois governos Lula (2002-2010) e o primeiro governo Dilma (2011-2014) consistem em enraizamento (institutional deepening) do processo prévio de mudança institucional.

"Brazil in Transition" possui inegáveis qualidades. Apoia-se em uma ampla análise temporal do Brasil que, cuidadosa, não cai na tentação de perder-se em detalhes históricos irrelevantes para a teoria que orienta a pesquisa. A abordagem que mistura contexto, liderança e ideias desafia teorias sobre o funcionamento das instituições como mecanismos estáticos e constitui inegável avanço no debate sobre como e por que as instituições mudam.

Uma leitura crítica, contudo, não pode deixar de apontar algumas omissões ou opções que o leitor julgue equivocadas. A seguir, nos detemos em alguns elementos que julgamos relevantes relativos à delimitação do objeto e consequências de opções teóricas e metodológicas que comprometem a capacidade do trabalho de explicar outros casos e de fazer avançar a teoria e a ciência social.

$\mathrm{O}$ fato de que os autores prometam (Alston, Melo, Mueller e Pereira, 2016, p. 20) analisar quatro períodos históricos, separando anos de FHC daqueles de Lula e depois Dilma, mas a versão final do livro englobe 1994-2014 numa mesma era é mais do que mera sobra de revisão. $\mathrm{O}$ argumento de que haveria enraizamento institucional e mudanças periféricas durante os governos do PT nos parece apressado, assim como a fusão Lula e Dilma como se não houvesse diferenças na forma como exerciam a liderança, na coalizão dominante que os sustentava e em várias ideias que carregavam.

Por exemplo, é certo que Lula optou por manter o tripé macroeconômico (câmbio flutuante, regime de metas de inflação e superávit primário), mas também promoveu aumento inédito de gastos sociais e uma política de apoio a empresas "campeãs nacionais". O primeiro governo Dilma, ao contrário, acabou marcado pela polêmica "nova matriz macroeconômica". Mais comprometedor é o fato de que não fica claro qual o indicador para qualificar um presidente como liderança (FHC) e não outros. Se pensarmos em 
tamanho da base de apoio, na aprovação de matérias e nos índices de popularidade, por exemplo, seria difícil considerar FHC o único líder da história recente.

Apesar de críticos quanto à capacidade dos especialistas em prever acontecimentos (Alston, Melo, Mueller e Pereira, 2016, p. 10) e reivindicar pouca arrogância epistemológica (p. 18) um dos objetivos do livro é justamente desenvolver uma teoria dedutiva que possa ser utilizada para prever o desenvolvimento futuro do Brasil e ser aplicada em outros casos. A análise da Argentina entre 1912 e 1946 mostra a fertilidade do marco teórico para explicar casos diferentes e sem viés confirmatório.

É o próprio caso do Brasil, contudo, que chega ao final do ano de publicação do livro (2016) tomando um rumo diferente do esperado. A expectativa de respeito geral pelas normas, estabilidade econômica e política claramente não se confirma. Que um trabalho qualitativo não seja capaz de prever com exatidão o desenrolar político de um país não é nada anormal, sobretudo ao utilizar uma análise contextual. Mas essa é a promessa do livro. Sua não confirmação decorre de alguns problemas de desenho e teoria que talvez merecessem maior atenção num trabalho desse fôlego e com ambição de criar uma teoria causal que explique fatores que levam à mudança institucional. Destacam-se três pontos dignos de nota nesse quesito: sua teoria dificilmente testável, uma visão otimista do processo de mudança institucional e a falta de consideração por, mesmo brevemente, explicações rivais.

Em primeiro lugar os autores propõem um modelo não muito parcimonioso. A teoria precisa simplificar o mundo e dirigir a atenção para um fenômeno ao mesmo tempo que se afasta de outros (Geddes, 2003, p. 20). O livro fala de desenvolvimento, causado por instituições, por sua vez causadas por crenças, que por sua vez dependem de um contexto específico e de lideranças específicas. Essa abordagem contextual deve ser mediada ao dar conta do estabelecimento de relações causais. Juntem-se as críticas feitas nas páginas anteriores aos problemas conceituais envolvendo a 
atribuição da qualidade de liderança e temos uma hipótese dificilmente falsificável.

Em segundo lugar, os autores são otimistas ao construírem um modelo no qual crenças viram instituições e instituições geram efeitos sem muito atrito. Existe uma consolidada agenda de pesquisa sobre instituições e seus outcomes e também sobre as variáveis independentes do processo de mudança institucional. Em geral, trata-se de literatura bastante consciente de suas limitações inferenciais, seja utilizando estudos comparativos, de caso ou quantitativos. São características da agenda neoinstitucional que se contrapõem ao "velho institucionalismo", que atribuía resultados a certos desenhos intitucionais.

Nesse sentido, a literatura sobre mudança institucional costuma enfatizar a qualidade de permanência das instituições, formais ou informais. Os conceitos de path dependence e logic of appropriateness poderiam ser utilizados para dar conta da permanência institucional. Crenças e instituições, formais ou informais, resistem à mudança, caso contrário não seria capazes de moldar o comportamento humano (cf, Pierson, 2004; March; Olsen, 1984) .

Por último, seria importante que o texto mencionasse algumas explicações rivais para a mudança das crenças e das instituições para evitar problemas de viés por omissão de variável. Qual o papel de grupos de interesse, de partidos políticos, da mídia e da própria mudança secular na mudança de crenças e instituições? Não seriam a liderança e as crenças apenas reflexos de mudanças no conjunto vencedor do status quo? Que outras explicações para o desenvolvimento deixam questões em aberto que o modelo dos autores seria capaz de responder?

"Brazil in Transition" é uma obra instigante, com uma abordagem promissora do processo de mudança institucional e do desenvolvimento. Ela nasce superada, não só porque não previu a incerteza dos fatos sociais e também por trazer embutidos elementos do velho institucionalismo ao ignorar a autonomia do Estado e de suas instituições, além de ignorar considerações mais contemporâneas sobre relações causais na pesquisa qualitativa ou sobre o papel de 
diferentes tipos de ideias na mudança institucional. Não obstante, chama atenção para fatores às vezes relegados pelos estudiosos de instituições, como as qualidades excepcionais (ou a falta delas) de lideranças políticas.

\section{Referências}

ALSTON, Lee; MELO, Marcus; MUELER, Bernardo; PEREIRA, Carlos. Brazil in Transition: beliefs, leadership, and institutional change (2016). Oxfordshire, Oxford University Press.

GEDDES, Barbara. Paradigms and Sand Castles: theory building and research design in comparative politics (2003). Ann Arbor: University of Michigan Press.

MARCH, James.; OLSEN, Johan (1984). “The New Institutionalism: organizational factors in political life”. American Political Science Review, Vol. LXX, VIII, III, 734:749.

PIERSON, Paul (2004). Politics in Time. history, institutions and social analysis. Princeton: University Press.

\section{Resumo}

O objetivo deste artigo e resenhar os principais argumentos do livro "Brazil in Transition: beliefs, leadership and institutional change" (2016), escrito por Lee J. Alston, Marcus André Melo, Bernardo Mueller e Carlos Pereira. Segundo os autores, o Brasil estaria pronto para realizar uma transição em direção ao desenvolvimento, fruto da adoção de instituições voltadas a garantir inclusão social e sustentabilidade fiscal. O objetivo do livro, portanto, é explicar o processo de mudança institucional nessa direção, causada por ideias trazidas por lideranças e implementadas em determinada janela de oportunidades. Após resenhar os principais argumentos dos autores, abordamos criticamente alguns pontos teóricos e metodológicos da obra.

Palavras-chave: Desenvolvimento econômico, Mudança institucional, Brasil

\section{Abstract}

This paper reviews the main arguments of the book "Brazil in Transition: beliefs, leadership and institutional change" (2016), wrote by Lee J. Alston, 
Marcus André Melo, Bernardo Mueller and Carlos Pereira. According to the authors, Brazil is in the verge of a transition to development, triggered by institutions focused on social inclusion and sound fiscal policy. The main aim of the book is to explain the process of institutional change, put forward in this direction by ideas brought up by leaderships and implemented through specific windows of opportunities. After review the author's main arguments we proceed critically addressing few theoretical and methodological issues.

Keywords: Economic development, Institutional change, Brazil

Recebido em: 13 de fevereiro de 2018

Aprovado em: 19 de março de 2018 